\title{
Experimental and Numerical Study on the Resistance Performance of an Axial Flow Cyclone Separator
}

\author{
Yigang Luan and Haiou Sun \\ College of Power and Energy Engineering, Harbin Engineering University, Heilongjiang 150001, China \\ Correspondence should be addressed to Haiou Sun; sunhaiou@hrbeu.edu.cn
}

Received 25 August 2014; Revised 23 December 2014; Accepted 23 December 2014

Academic Editor: Junwu Wang

Copyright ( 2015 Y. Luan and H. Sun. This is an open access article distributed under the Creative Commons Attribution License, which permits unrestricted use, distribution, and reproduction in any medium, provided the original work is properly cited.

\begin{abstract}
The purpose of this paper is to study the pressure drop of an axial flow cyclone separator as a function of inlet velocities using experimental and computational fluid dynamics (CFD) methods. First, the resistance performance of the separator was acquired under ambient pressure and temperature with little change by wind tunnel experiments. Then, numerical simulations were carried out in CFD code Fluent 6.3 under standard operating conditions. A comparison between the experimental and CFD data demonstrates that the CFD method can predict the pressure drop of the axial cyclone separator excellently. Additionally, the results show that the axial flow cyclone separators have a pressure drop coefficient of approximately 7.5. To study the effect of ambient pressure and temperature on pressure drops, the same CFD method was employed to predict the resistance performance under various operating conditions. Then the numerical results were compared with the data of a normalization process method of pressure drops raised in this paper. Their comparison demonstrated that the normalization method had a high precision in predicting the influence of ambient operating parameters on pressure drops of an axial flow cyclone separator.
\end{abstract}

\section{Introduction}

Separation technology has a dominant role in many process industries. Cyclone separators, which were developed in the last decades of 19th century, are devices that employ a centrifugal force generated by a swirling gas flow to separate particles from a carrier gas. Due to the relative simplicity, ease and low construction and operation, low space requirement, absence of moving parts, and adaptability to a wide range of operating conditions, cyclones have been considered the oldest and most commonly used industrial particulate control devices [1-7]. With the use of suitable materials and methods of construction, cyclones are particularly well suited for high temperature and pressure conditions. Depending on the size of the cyclones, the gas flow across cyclones has a wide range [8].

Cyclone design has remained largely unchanged for over a century. In general, cyclone designs are of two types: the straight-through cyclone and the more common conventional reverse flow cyclone. The reverse flow cyclone shown in Figure 1 is the most frequently used in the industry [3].
The cyclone usually consists of both conical and cylindrical parts, which together form the body of the cyclone, the inlet pipe, which is mounted tangentially onto the side wall of the cylindrical part near the top of the cyclone, the separation chamber, the dust chamber, and the vortex finder also called vortex tube, which is fixed on the top of the cyclone and protrudes some distance into the body of the cyclone. The separation process in cyclone separators is caused by centrifugal forces. Rotational gas flow is produced by the tangential inlet. Particles contained in the gas flow are forced radially outward to the wall by centrifugal force due to its swirling motion. The particles move downwards along the cylindrical and conical wall towards the lower part of the cyclone, called the apex, and into the dust outlet, where they are collected. The clean gas leaves the cyclone upwards through the centrally arranged vortex tube.

Collection efficiency, fractional efficiencies, and pressure drop are the main performance characteristics of cyclones. Since its inception over a century ago, many researchers have contributed to the large volume of work to improve the cyclone performance, and extensive experimental work has 


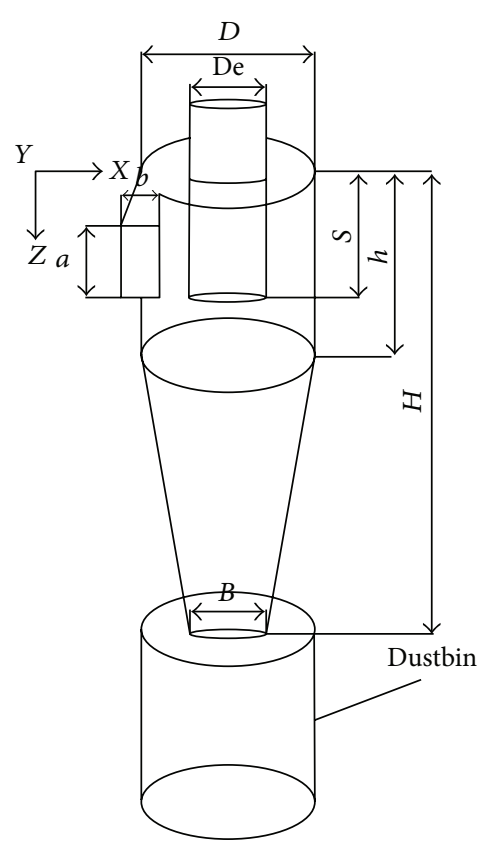

FIgURE 1: Schematic of traditional cyclone separators.

been done to explain their flow characteristics [9-13]. Among these, Stairmand presented one of the most popular design guides, which suggested the ratio of the cylinder height and exit tube length of the cyclone body diameter for the design of a high efficiency cyclone, and was called the Stairmand high-efficiency cyclone structure. Zhu and Lee have conducted extensive experiments on cyclones of different heights and different vortex finder lengths and found that these parameters can influence the separation efficiency of cyclones considerably.

With the rapid development of the computer and computational fluid dynamics techniques, the use of numerical simulations to predict the performance of the cyclone has received much attention, and CFD method is at present under intensive development $[14,15]$. This can reduce some of the very costly real-life experimental investigations. In fact, there have been a number of investigations into numerical simulations on the fluid flow and particle trajectories in cyclones. One of the first CFD simulations was completed by Boysan, who conducted numerical studies on viscous fluid flow and tracked the particle motion to predict the particle separation efficiency of cyclones [10]. Gimbun et al. used the CFD method to predict and evaluate the effects of temperature on the pressure drop of cyclone separators and compared the results with four empirical models and the experimental data available. Their results demonstrated that the CFD method can be used in cyclone design for any operating conditions [16]. H. Safikhani et al. employed CFD techniques to characterize the performance of three types of standard cyclones. The flow field parameters, such as the velocity and turbulence intensity at different flow rates, were investigated in detail. In addition the pressure drop was computed and compared with the experimental data with good agreement.
TABLE 1: Geometrical dimensions of the axial flow cyclone separator (units in $\mathrm{mm}^{\circ}{ }^{\circ}$ ).

\begin{tabular}{lccccccc}
\hline Geometry & $L$ & $l$ & $D$ & $D 1$ & $d$ & $h$ & De \\
\hline Value & 0.14 & 0.045 & 0.14 & 0.09 & 0.03 & 0.045 & 45 \\
\hline
\end{tabular}

Much research has been done on the conventional reverse flow cyclone, while little can be found on the straightthrough cyclone, shown in Figure 2, from the aforementioned literature. The axial flow cyclone separator operates on the same principle as the tangential inlet cyclone, and separation is achieved from the centrifugal force field generated by swirling the material inside the cyclone, but they differ in the manner in which they achieve the swirling action. In the axial flow cyclone, the material enters the cylindrical section centrally, and the swirling motion is formed by the cured vanes. I. K. Kim and J. S. Kim employed numerical and experimental methods to investigate the influence of dimensional modification on the pressure and dust separation efficiency of axial inlet cyclones [17]. Compared to the conventional cyclone, the axial inlet cyclone provides higher throughputs and greater flexibility over the separation process [18].

The main objective of this study was to analyze the composition of the pressure drop over an axial flow cyclone separator, via experimental and CFD modeling methods. Numerical simulations are presented by the commercial CFD software Fluent 6.3. The effects of ambient pressure and temperature on the cyclone resistance performance are investigated by the numerical method. Then, we establish a universal model for its prediction by employing the measured pressure drops of cyclones to normalize the effects of ambient parameters. A schematic of the axial cyclone studied is shown in Figure 1. The cyclone dimensions used in this simulation are listed in Table 1.

\section{Experimental Study}

To study the resistance performance of the axial flow cyclone separator by the experimental method, a small-scale wind tunnel test system was constructed, as illustrated schematically in Figure 3. Air was introduced to the cyclone separator axially by a centrifugal blower. The inlet-air flow rate was measured by a double-torsion-line flowmeter. The flow rate was regulated by changing the speed of the blower by a transducer. To guarantee that the flow was fully developed, flow regulator devices were added before and after the test axial cyclone separators.

The test cyclone is made of plexiglass, as shown in Figure 4, and its major dimensions are listed in Table 1. Experiments were conducted under a natural ambient environment by changing the inlet velocities, and the pressure drops were measured by the near-wall static pressure difference before and after the cyclone separator, as shown in Figure 5, using a digital micro-manometer (TSI Model 8386). To guarantee the accuracy of the results, repeated experiments were conducted under ambient parameters with little change. The detailed operating conditions and results are listed in Tables 2, 3, and 4. 


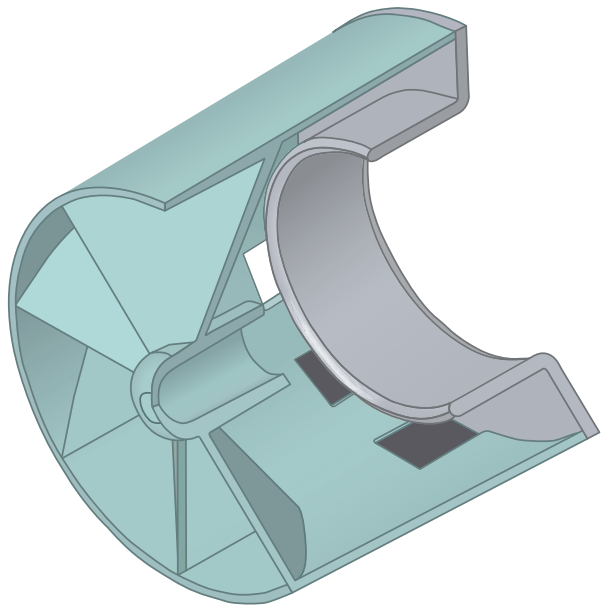

(a)

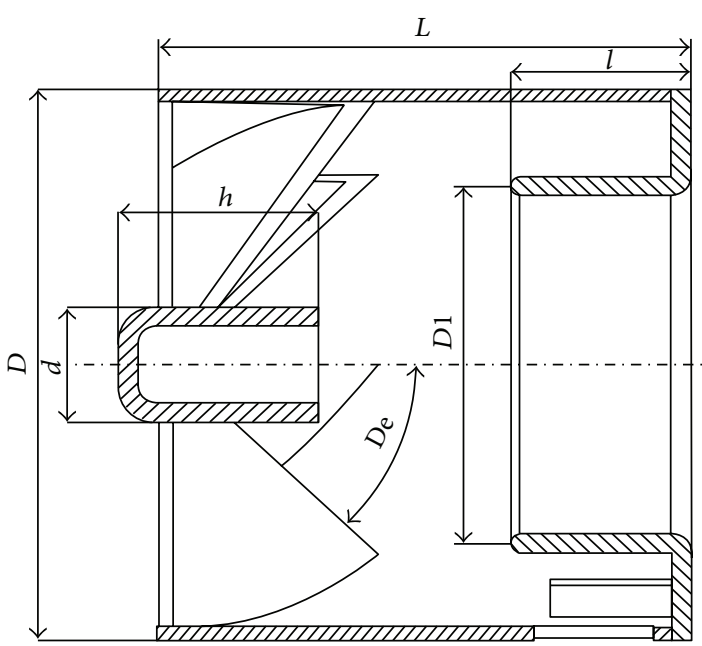

(b)

FIGURE 2: Geometry of the axial flow cyclone separator.

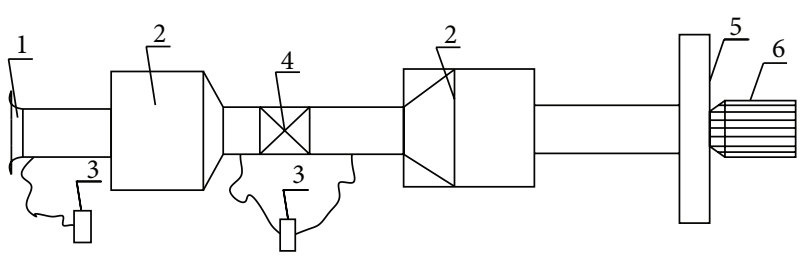

Figure 3: The layout of the experimental device 1. Double-torsionline flowmeter 2. Regulator device 3. Digital micro-manometer 4 . Axial flow cyclone separator 5. Blower 6. Motor.

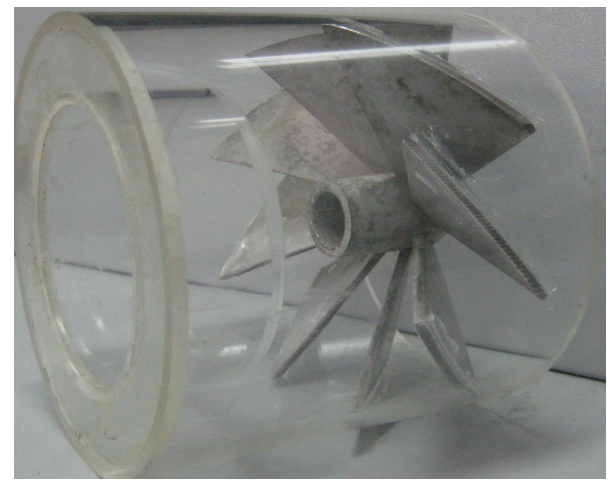

FIGURE 4: View of axial cyclone separator.

\section{CFD Method}

With the rapid development of computer and computational fluid dynamics techniques, the CFD method has proven to be a promising tool to investigate the flow field and pressure drop characteristics inside the cyclone. For the complicated turbulent swirling flow, the key to the success of CFD lies with the accurate description of the turbulent behavior of the flow. Fluent is a commercially available CFD code used

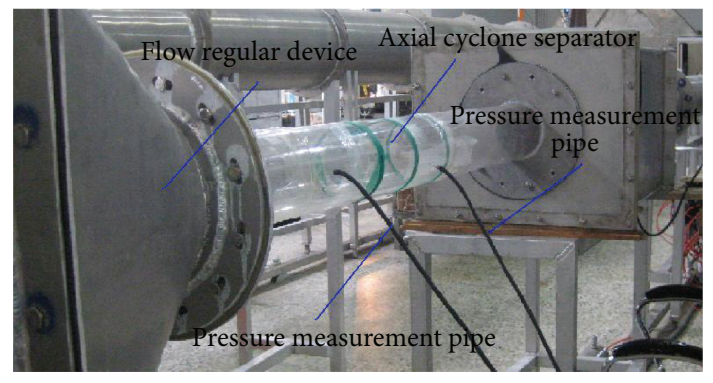

FIGURE 5: View of test section.

to carry out coupled or segregated calculations. It is ideally suited for incompressible to mildly compressible flows. To model the swirling turbulent flow in a cyclone separator, there are a number of turbulence models available in Fluent. In this paper, the realizable $k-\varepsilon$ model was employed to predict the pressure distribution inside the axial cyclone separator and its resistance performance under various operating conditions.

3.1. Governing Equations. The gas flow through the axial cyclone separator is turbulent in all cases, even though the Reynolds number varies considerably. Based on the Boussinesq hypothesis, the Reynolds-averaged Navier-Stokes equations were solved to predict the continuous phase. Ignoring the mass forces, the equations are described as follows [19].

Continuous conservation equation:

$$
\frac{\partial \rho}{\partial t}+\frac{\partial}{\partial x_{i}}\left(\rho u_{i}\right)=0 \text {. }
$$

Momentum conservation equation:

$$
\frac{\partial}{\partial t}\left(\rho u_{i}\right)+\frac{\partial}{\partial x_{j}}\left(\rho u_{i} u_{j}\right)=-\frac{\partial p}{\partial x_{i}}+\frac{\partial \tau_{i j}}{\partial x_{j}} .
$$


TABLE 2: Resistance performance of axial flow cyclone separator under $P_{a}=99220 \mathrm{~Pa}$ and $T_{a}=23.0^{\circ} \mathrm{C}$.

\begin{tabular}{lccccccc}
\hline Inlet velocity $(\mathrm{m} / \mathrm{s})$ & 2.9 & 3.4 & 4.2 & 5.3 & 6.0 & 6.9 & 7.6 \\
Pressure drop $(\mathrm{Pa})$ & 36 & 49 & 75 & 118 & 151 & 208 & 251 \\
Inlet velocity $(\mathrm{m} / \mathrm{s})$ & 8.6 & 9.2 & 10.4 & 11.3 & 12.5 & 13.3 & 14.6 \\
Pressure drop $(\mathrm{Pa})$ & 318 & 375 & 476 & 554 & 683 & 779 & 940 \\
\hline
\end{tabular}

TABLE 3: Resistance performance of axial flow cyclone separator under $P_{a}=98420 \mathrm{~Pa}$ and $T_{a}=26.8^{\circ} \mathrm{C}$.

\begin{tabular}{lccccccc}
\hline Inlet velocity $(\mathrm{m} / \mathrm{s})$ & 3.4 & 4.2 & 5.3 & 5.9 & 6.9 & 7.6 & 8.6 \\
Pressure drop $(\mathrm{Pa})$ & 50 & 73 & 115 & 149 & 204 & 311 \\
Inlet velocity $(\mathrm{m} / \mathrm{s})$ & 9.2 & 10.4 & 11.3 & 12.5 & 13.3 & 14.6 \\
Pressure drop $(\mathrm{Pa})$ & 363 & 461 & 542 & 669 & 916 & 916 \\
\hline
\end{tabular}

TABLE 4: Resistance performance of axial flow cyclone separator under $P_{a}=99100 \mathrm{~Pa}$ and $T_{a}=25.3^{\circ} \mathrm{C}$.

\begin{tabular}{|c|c|c|c|c|c|c|c|}
\hline Inlet velocity $(\mathrm{m} / \mathrm{s})$ & 3.5 & 5.2 & 6.9 & 8.5 & 10.3 & 12.4 & 14.5 \\
\hline Pressure drop $(\mathrm{Pa})$ & 52 & 118 & 205 & 313 & 467 & 676 & 925 \\
\hline
\end{tabular}

Energy conservation equation:

$$
\begin{aligned}
\frac{\partial}{\partial t} & {\left[\rho\left(e+\frac{u_{i} u_{i}}{2}\right)\right]+\frac{\partial}{\partial x_{j}}\left\{u_{j}\left[\rho\left(e+\frac{u_{i} u_{i}}{2}\right)+p\right]\right\} } \\
& =\frac{\partial}{\partial x_{i}}\left(k \frac{\partial T}{\partial x_{i}}+u_{j} \tau_{i j}\right) .
\end{aligned}
$$

State equation:

$$
\frac{p}{\rho}=R T
$$

where

$$
\tau_{i j}=\left(\mu+\mu_{T}\right)\left(\frac{\partial u_{i}}{\partial x_{j}}+\frac{\partial u_{j}}{\partial x_{i}}\right)-\frac{2}{3} \delta_{i j}\left(\mu+\mu_{T}\right) \frac{\partial u_{k}}{\partial x_{k}}
$$

3.2. Turbulence Model. The two-equation turbulence model, realizable $k-\varepsilon$ model, was used to simulate the turbulence transport effects. The transport equations for $k$ and $\varepsilon$ in the realizable $k-\varepsilon$ model are as follows:

$$
\begin{aligned}
\frac{\partial(\rho k)}{\partial t}+\frac{\partial\left(\rho k u_{i}\right)}{\partial x_{i}}= & \frac{\partial}{\partial x_{i}}\left[\left(\mu+\frac{\mu_{T}}{\sigma_{k}}\right) \frac{\partial k}{\partial x_{i}}\right]+G_{k}+G_{b} \\
& -\rho \varepsilon-Y_{M}+S_{k} \\
\frac{\partial(\rho \varepsilon)}{\partial t}+\frac{\partial\left(\rho \varepsilon u_{i}\right)}{\partial x_{i}}= & \frac{\partial}{\partial x_{i}}\left[\left(\mu+\frac{\mu_{T}}{\sigma_{\varepsilon}}\right) \frac{\partial \varepsilon}{\partial x_{i}}\right] \\
& +\rho C_{1} S \varepsilon-\rho C_{2} \frac{\varepsilon^{2}}{k+\sqrt{v \varepsilon}} .
\end{aligned}
$$

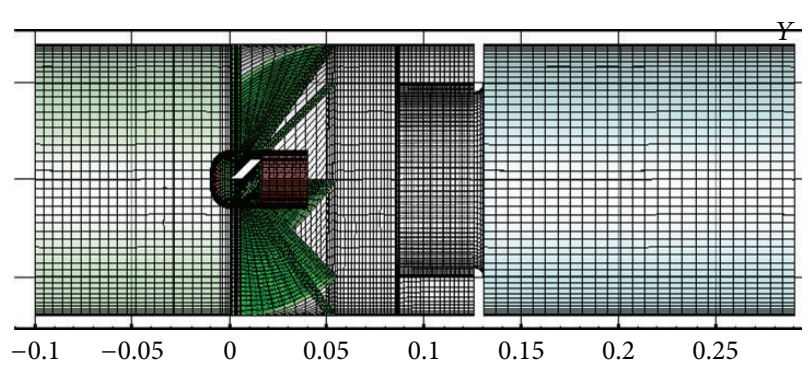

Figure 6: Computational mesh used in simulation.

The model constants have been determined from the experiments and are given as follows:

$$
\begin{gathered}
C_{1 \varepsilon}=1.44, \quad C_{2 \varepsilon}=1.9, \quad C_{\mu}=0.09, \\
\sigma_{k}=1.0, \quad \sigma_{\varepsilon}=1.2 .
\end{gathered}
$$

3.3. Computational Grid and Boundary Conditions. The equations were solved numerically by the finite volume method using the commercial code Fluent 6.3. According to the basic idea of the control volume method, the computational domain was divided into a number of cells. To reflect the realistic boundary of the cyclone separator, a hybrid mesh was adopted for the simulation. The hexahedral and wedge-shaped grids were generated by dividing the whole domain inside the cyclone into several subzones and meshing each zone separately. Figure 6 shows the computational domain, containing about 300,000 CFD cells. At the zone near the wall and vortex finder, the grids are dense, while at the zone away from the wall, the grids are refined. The computational field is extruded to an extent at the inlet and outlet of the separator. Extensive grid refinement tests 
were conducted on the flow field of the cyclone to ensure that the solution was not grid dependent.

The presto interpolation scheme for pressure, the SIMPLEC algorithm for pressure-velocity coupling, and a twoorder upwind interpolation scheme for momentum variables were used to acquire satisfactory results in the cyclones. Due to the difficulty of reaching convergence in simulations, the first-order upwind scheme was applied for an initial result. Numerical simulations were carried out with an accuracy of $10 e-4$ for all the scaled residuals. The gas flow was assumed to be at standard temperature and pressure, and the average inlet velocity was specifically changed from $1 \mathrm{~m} / \mathrm{s}$ to $14 \mathrm{~m} / \mathrm{s}$.

The boundary condition at the cyclone inlet was set as the pressure inlet, and the pressure was assumed to be $101325 \mathrm{~Pa}$ at different conditions. The pressure outlet boundary condition was used at the exit, and static pressure was set to some value until the average gas velocity at the inlet boundary was needed. At the walls, no-slip boundary condition was applied for the velocity, and a near-wall treatment was achieved by using an enhanced wall treatment. The CFD simulation was performed with a Pentium core (TM) i5 $7502.67 \mathrm{GHz}$ PC with 512 cache-memory, 3 G RAM-memory, and 500 GB hard disc memory.

\section{Results and Discussion}

4.1. Comparison between CFD Data and Experimental Result. The experimental results were acquired under different operating conditions, while the CFD data were obtained under a standard ambient pressure and at a temperature of $300 \mathrm{~K}$. To compare the two methods, the standard pressure drop was raised to ensure they were under the same conditions. The pressure drops under an ambient pressure of 101,325 Pa and a temperature of $300 \mathrm{~K}$ with a certain inlet velocity were defined as the standard value. The pressure drop under different conditions can be converted to the corresponding standard value by

$$
\Delta p \frac{T}{P}=\Delta p_{s} \frac{T_{s}}{P_{s}},
$$

where $\Delta p_{s}$ is the standard pressure drop under a certain inlet velocity, $T_{s}=300 \mathrm{~K}$, and $P_{s}=101325 \mathrm{~Pa}$.

Using this transformation method, the experimental data can be compared with the CFD result. The pressure drop comparison between the experiment and CFD data is shown in Figure 7. From this figure, a very small pressure drop deviation in the CFD numerical calculations is observed, with less than $2 \%$ deviation at different inlet velocities. The comparison results show that the results computed in the present study show better agreement with the experimental data for the pressure drop, and the numerical model employed in this paper is suitable for predicting the resistance performance of axial flow cyclone separators.

Usually, the pressure drop of cyclones is proportional to the inlet dynamic pressure and can be presented as follows:

$$
\Delta p=\xi \frac{1}{2} \rho v^{2}
$$

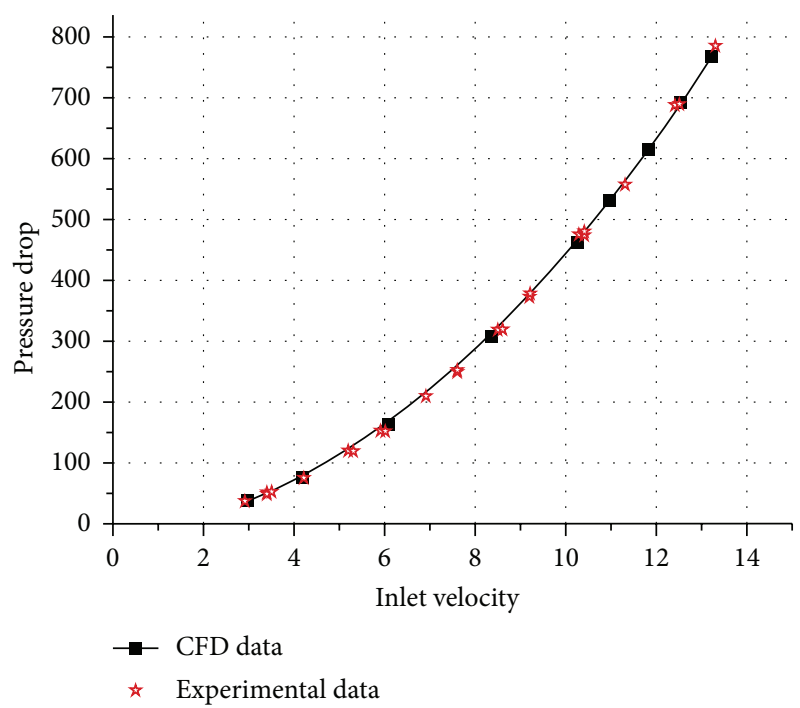

FIGURE 7: Comparison between experimental and CFD data.

where $\xi, \rho$, and $v$ are the pressure drop coefficient, gas density, and inlet velocity, respectively. It points out that the pressure drop increases with any increase in the inlet velocity. Both the experimental and CFD data display that characteristic. The pressure drop coefficient of the axial flow cyclone separator studied in the paper was approximately 7.5.

4.2. Numerical Simulation Results. To understand the pressure drop of the axial flow cyclone separator in detail, Figures 8 to 11 are the distribution of the static and total pressure contours on several sections with the inlet velocity of $4 \mathrm{~m} / \mathrm{s}$.

Figures 8 and 9 show the static pressure contours on different sections inside the axial cyclone separators. The static pressure decreased gradually at first and improved slightly along the axial flow direction from the inlet to outlet of the cyclone separators, and the minimum static pressure zone existed behind the swirl vane. The pressure gradient was larger near the swirl vanes and the outlet zones inside cyclones.

Figures 10 and 11 show the total pressure contours on different sections inside the axial cyclone separators. We can see clearly that the pressure decreased gradually along the flow direction, and the pressure gradient behind the axial cyclone and near the outlet was larger than at other places. Therefore these two zones significantly contributed to the pressure drop of axial flow cyclone separators.

4.3. Effect of Ambient Pressure and Temperature on the Pressure Drop. To validate the accuracy of (8) and to study the effect of ambient pressure and temperature on the pressure drop of axial flow cyclone separators, the pressure drop under different operating conditions was simulated with the CFD method used above and was predicted by (8). The partial results are listed in Tables 5 and 6. 


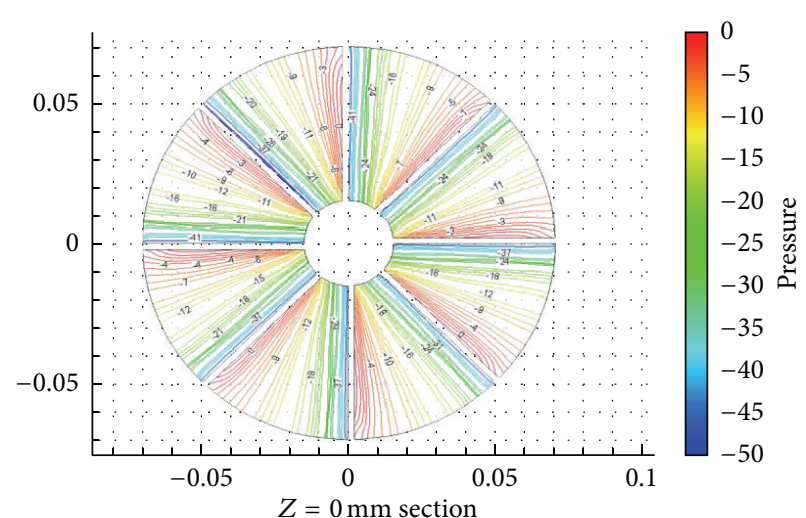

(a)

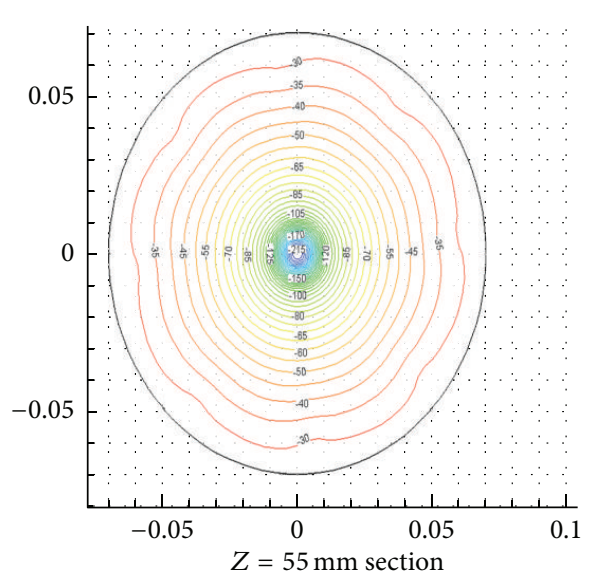

(c)

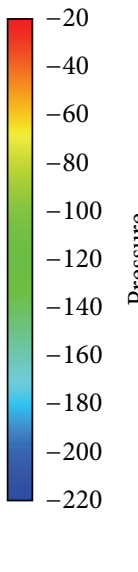

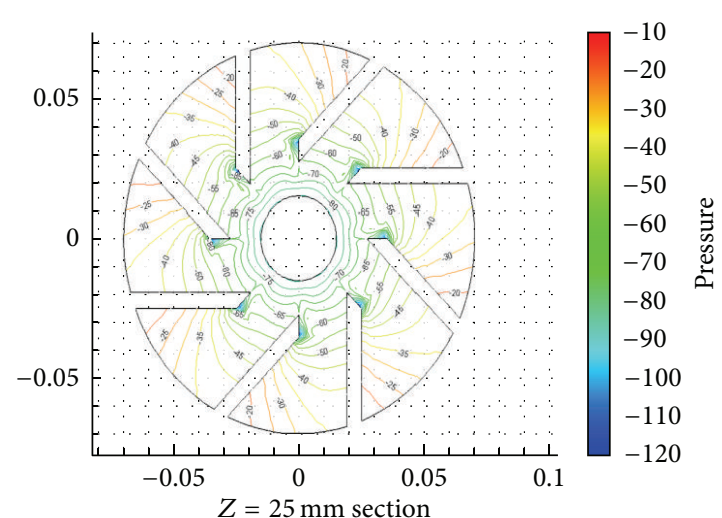

(b)

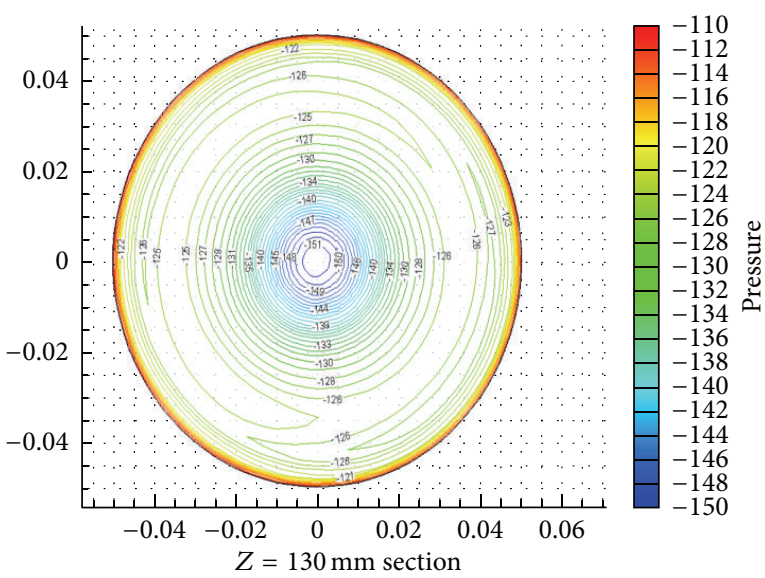

(d)

FIGURE 8: Contours of static pressure in cross section.

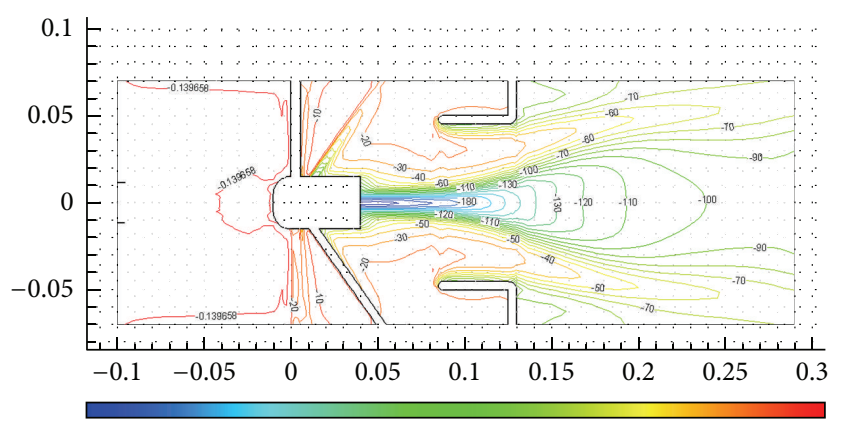

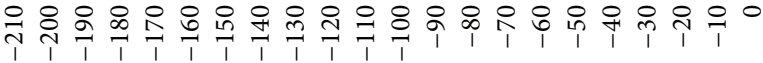

FIGURE 9: Contours of static pressure in the vertical section.

The comparison results show that the maximal relative error is no more than $0.5 \%$; hence (8) can be used to predict the pressure drop of the axial cyclone separator with the same inlet velocity under different conditions. Additionally we can see clearly that the pressure drop across the axial flow cyclone separators depended greatly on the operating conditions. With the same inlet velocity, the pressure drop decreased greatly with the increasing of temperature if the ambient pressure is unchangeable, while the pressure drop increased linearly with the increment of ambient pressure when keeping the ambient temperature constant.

\section{Conclusions}

In this study, an investigation into the resistance performance of an axial flow cyclone separators was carried out by both experimental and CFD methods. Wind-tunnel experiments were carried out to evaluate the pressure drop of the cyclones as a function of the inlet velocities. Then, the CFD code Fluent 6.3 with the realizable $k$ - $\varepsilon$ two-equation turbulence model was employed to predict the resistance performance of the same cyclone separator under standard operating conditions. To make the comparison between the experimental and CFD data, the experimental data was converted to a standard value of the same inlet velocity by a normalization method raised in this paper. Good agreement was obtained between the CFD predictions and the experimental data, with less than $2 \%$ deviation. Therefore the CFD simulation is a promising method for predicting the resistance performance of the axial flow cyclone separator studied in this paper. 


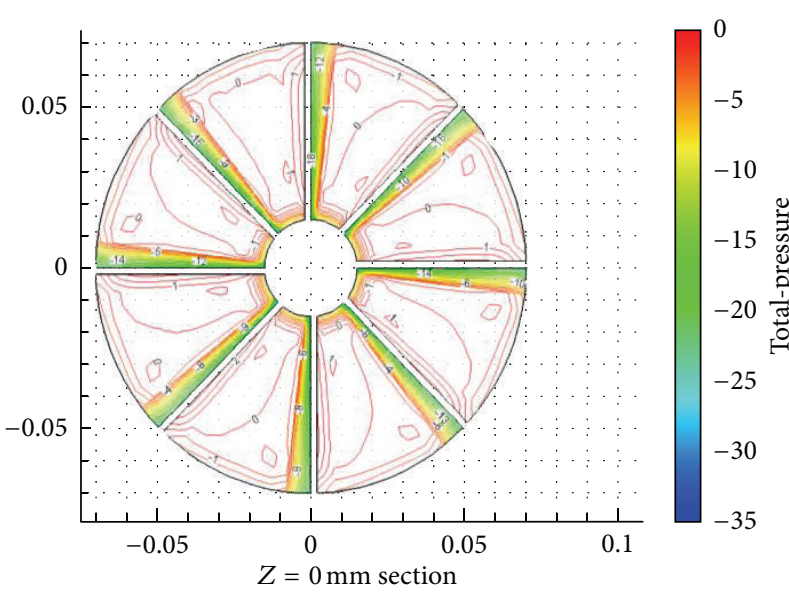

(a)

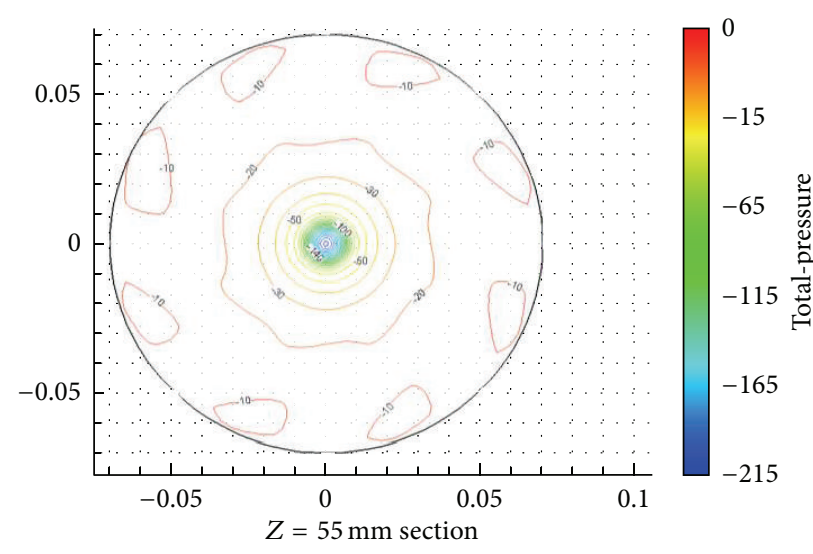

(c)

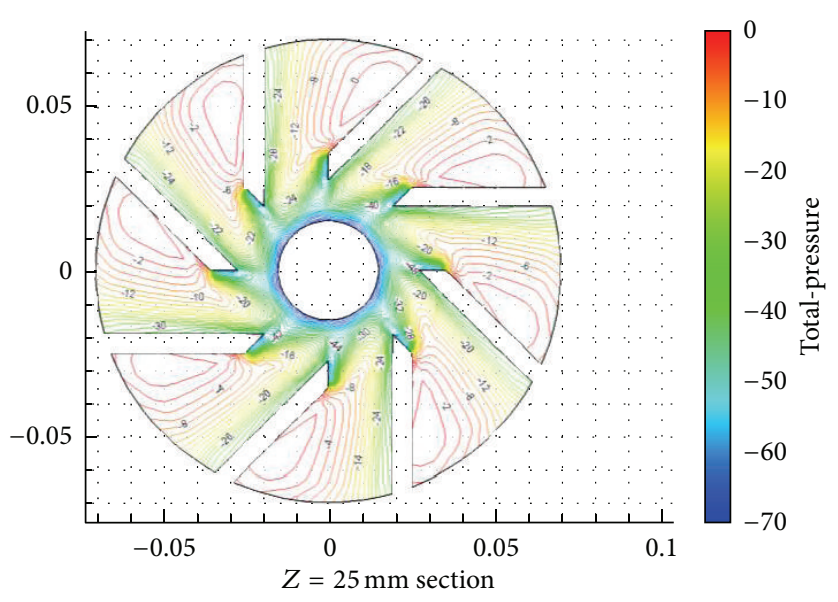

(b)

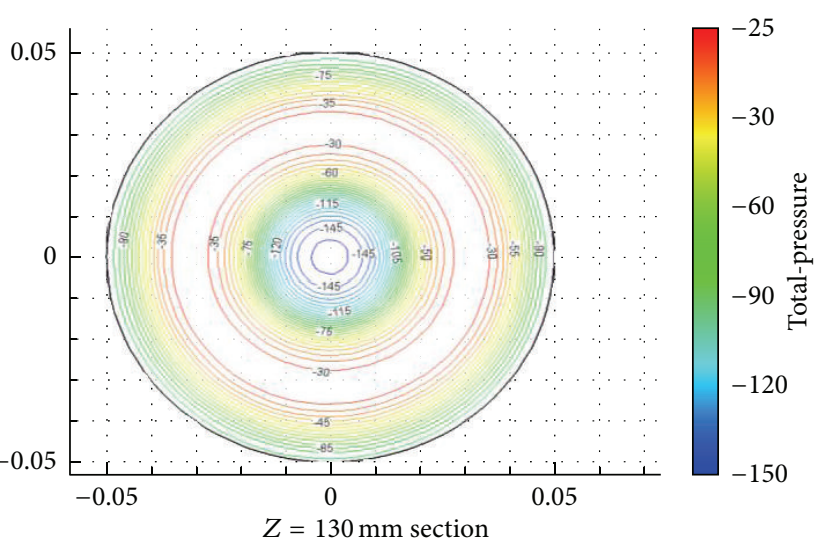

(d)

FIGURE 10: Contours of total pressure in vertical section.

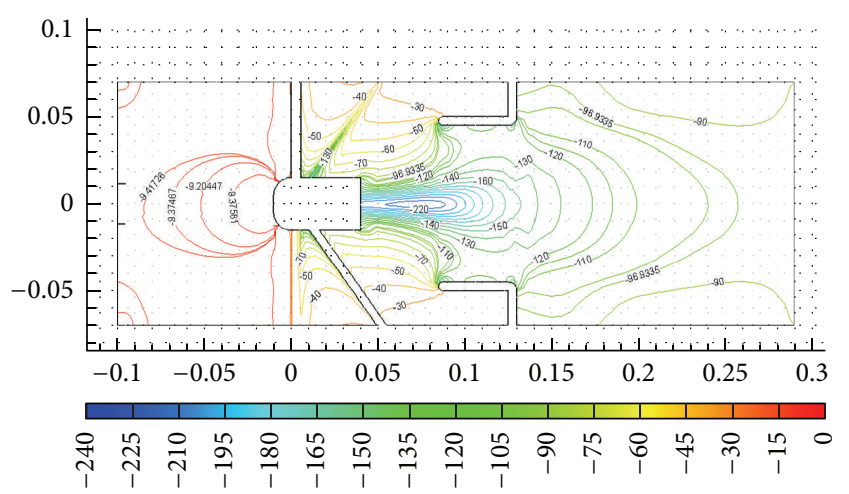

FIGURE 11: Contours of total pressure in cross section.

The experimental and CFD data show that the pressure drop can be written as a function of the inlet velocity head. The pressure drop coefficient of the axial flow cyclone separator is approximately 7.5. To study the effect of the ambient pressure and temperature on the pressure drops of an axial cyclone separator, pressure drops under various conditions were attained by the CFD method mentioned above and compared with the predicted value by the standard value formula. The comparison results show that the standard value formula can be used to predict the effect of ambient pressure and temperature on the resistance performance of the axial flow cyclone separators with high precision.

\section{Abbreviations and Acronyms}

L: $\quad$ Cyclone cylinder height $(\mathrm{m})$

$l$ : Cyclone gas outlet height (m)

$D$ : Cyclone cylinder diameter (m)

$D$ 1: Cyclone gas outlet diameter $(\mathrm{m})$

$d$ : Swirl vane axis diameter $(\mathrm{m})$

$h$ : Swirl vane axis height $(\mathrm{m})$

De: Swirl vane degree $\left({ }^{\circ}\right)$

$P_{a}$ : Ambient pressure $(\mathrm{Pa})$

$T_{a}$ : Ambient temperature $\left({ }^{\circ} \mathrm{C}\right.$ or $\left.\mathrm{K}\right)$

$\tau_{i j}$ : The stress tensor $\left(\mathrm{Kg} /\left(\mathrm{m} \cdot \mathrm{s}^{2}\right)\right)$

$\rho:$ The gas density $\left(\mathrm{kg} / \mathrm{m}^{3}\right)$

$u_{i}$ : The velocity component $(\mathrm{m} / \mathrm{s})$

$p$ : The static pressure $(\mathrm{Pa})$ 
TABle 5: Pressure drop of axial flow cyclone separator with inlet velocity of $4 \mathrm{~m} / \mathrm{s}$.

\begin{tabular}{|c|c|c|c|c|c|c|c|}
\hline Number & 1 & 2 & 3 & 4 & 5 & 6 & 7 \\
\hline Ambient pressure $(\mathrm{Pa})$ & 101325 & 201325 & 251325 & 101325 & 151325 & 201325 & 251325 \\
\hline Ambient temperature $(\mathrm{K})$ & 300 & 300 & 300 & 350 & 350 & 350 & 350 \\
\hline Pressure drop by CFD $(\mathrm{Pa})$ & 70.32 & 139.37 & 173.89 & 60.29 & 89.98 & 119.61 & 149.26 \\
\hline Pressure drop by (8) (Pa) & $\mathrm{X}$ & 139.72 & 174.42 & 60.27 & 90.02 & 119.76 & 149.50 \\
\hline Relative error (\%) & $\mathrm{X}$ & -0.08 & 0.31 & -0.002 & 0.04 & 0.13 & 0.16 \\
\hline Number & 8 & 9 & 10 & 11 & 12 & 13 & 14 \\
\hline Ambient pressure $(\mathrm{Pa})$ & 101325 & 151325 & 201325 & 251325 & 101325 & 151325 & 201325 \\
\hline Ambient temperature (K) & 400 & 400 & 400 & 400 & 450 & 450 & 450 \\
\hline Pressure drop by $\mathrm{CFD}(\mathrm{Pa})$ & 52.87 & 78.84 & 104.80 & 130.78 & 47.08 & 70.18 & 93.28 \\
\hline Pressure drop by $(8)(\mathrm{Pa})$ & 52.74 & 78.77 & 104.79 & 130.82 & 46.88 & 70.01 & 93.15 \\
\hline Relative error (\%) & -0.25 & -0.09 & -0.01 & 0.03 & -0.42 & -0.24 & -0.14 \\
\hline Number & 15 & 16 & 17 & 18 & 19 & 20 & 21 \\
\hline Ambient pressure $(\mathrm{Pa})$ & 251325 & 101325 & 151325 & 201325 & 251325 & $\mathrm{X}$ & $\mathrm{X}$ \\
\hline Ambient temperature $(\mathrm{K})$ & 450 & 500 & 500 & 500 & 500 & $\mathrm{X}$ & $\mathrm{X}$ \\
\hline Pressure drop by CFD (Pa) & 116.36 & 42.40 & 63.17 & 93.28 & 104.85 & $\mathrm{X}$ & $\mathrm{X}$ \\
\hline Pressure drop by (8) $(\mathrm{Pa})$ & 116.28 & 42.19 & 63.01 & 93.15 & 104.65 & $\mathrm{X}$ & $\mathrm{X}$ \\
\hline Relative error (\%) & -0.07 & -0.49 & -0.25 & -0.14 & -0.19 & $\mathrm{X}$ & $\mathrm{X}$ \\
\hline
\end{tabular}

TABle 6: Pressure drop of axial flow cyclone separator with inlet velocity of $10 \mathrm{~m} / \mathrm{s}$.

\begin{tabular}{|c|c|c|c|c|c|c|c|}
\hline Number & 1 & 2 & 3 & 4 & 5 & 6 & 7 \\
\hline Ambient pressure $(\mathrm{Pa})$ & 81500 & 99000 & 150000 & 151500 & 201500 & 101500 & 99000 \\
\hline Ambient temperature $(\mathrm{K})$ & 253 & 253 & 253 & 253 & 253 & 273 & 283 \\
\hline Pressure drop by CFD (Pa) & 418.82 & 508.99 & 769.38 & 778.32 & 1032.45 & 484.32 & 455.08 \\
\hline Pressure drop by (8) (Pa) & 418.69 & 508.60 & 770.60 & 778.31 & 1035.18 & 483.24 & 454.68 \\
\hline Relative error (\%) & -0.03 & -0.08 & 0.16 & -0.002 & 0.26 & -0.22 & -0.09 \\
\hline Number & 8 & 9 & 10 & 11 & 12 & 13 & 14 \\
\hline Ambient pressure $(\mathrm{Pa})$ & 81500 & 99000 & 101325 & 101500 & 101325 & 202750 & 303975 \\
\hline Ambient temperature $(\mathrm{K})$ & 300 & 300 & 300 & 300 & 400 & 400 & 400 \\
\hline Pressure drop by CFD (Pa) & 354.38 & 429.60 & 438.99 & 439.96 & 330.84 & 660.64 & 989.41 \\
\hline Pressure drop by $(8)(\mathrm{Pa})$ & 353.10 & 428.92 & $\mathrm{X}$ & 439.75 & 329.24 & 658.81 & 987.73 \\
\hline Relative error (\%) & -0.36 & -0.09 & $\mathrm{X}$ & -0.05 & -0.48 & -0.28 & -0.17 \\
\hline
\end{tabular}

e: $\quad$ The inner energy $(\mathrm{J})$

$k$ : The thermal conductivity $(\mathrm{W} /(\mathrm{m} \cdot \mathrm{K}))$

$T$ : The temperature (K)

$\mu: \quad$ The molecular viscosity $(\mathrm{Pa} \cdot \mathrm{s})$

$\mu_{T}$ : The turbulent viscosity $(\mathrm{Pa} \cdot \mathrm{s})$

$\Delta p$ : The pressure drop of cyclone $(\mathrm{Pa})$

$\xi$ : The pressure drop coefficient of cyclone.

\section{Conflict of Interests}

The authors declare that there is no conflict of interests regarding the publication of this paper.

\section{Acknowledgment}

The authors gratefully acknowledge the financial assistance from Fundamental Research Funds for the Central Universities (Project no. HEUCF140310).

\section{References}

[1] R. B. Xiang and K. W. Lee, "Numerical study of flow field in cyclones of different height," Chemical Engineering and Processing, vol. 44, no. 8, pp. 877-883, 2005.

[2] Y. Jo, C. Tien, and M. B. Ray, "Development of a post cyclone to improve the efficiency of reverse flow cyclones," Powder Technology, vol. 113, no. 1-2, pp. 97-108, 2000.

[3] F. Qian, Z. Huang, G. Chen, and M. Zhang, "Numerical study of the separation characteristics in a cyclone of different inlet particle concentrations," Computers \& Chemical Engineering, vol. 31, no. 9, pp. 1111-1122, 2007.

[4] A. Kępa, "Division of outlet flow in a cyclone vortex finder-the CFD calculations," Separation and Purification Technology, vol. 75, no. 2, pp. 127-131, 2010.

[5] H. Yoshida, Y. Nishimura, K. Fukui, and T. Yamamoto, "Effect of apex cone shape on fine particle classification of gas-cyclone," Powder Technology, vol. 204, no. 1, pp. 54-62, 2010. 
[6] B. Zhao, "Modeling pressure drop coefficient for cyclone separators: a support vector machine approach," Chemical Engineering Science, vol. 64, no. 19, pp. 4131-4136, 2009.

[7] K. Elsayed Khairy and C. Lacor, "Optimization of the cyclone separator geometry for minimum pressure drop using mathematical models and CFD simulations," Chemical Engineering Science, vol. 65, no. 22, pp. 6048-6058, 2010.

[8] S. Obermair, J. Woisetschläger, and G. Staudinger, "Investigation of the flow pattern in different dust outlet geometries of a gas cyclone by laser Doppler anemometry," Powder Technology, vol. 138, no. 2-3, pp. 239-251, 2003.

[9] B. Zhao, Y. Su, and J. Zhang, "Simulation of gas flow pattern and separation efficiency in cyclone with conventional single and spiral double inlet configuration," Chemical Engineering Research and Design, vol. 84, no. 12, pp. 1158-1165, 2006.

[10] W. D. Griffiths and F. Boysan, "Computational fluid dynamics (CDF) and empirical modelling of the performance of a number of cyclone samplers," Journal of Aerosol Science, vol. 27, no. 2, pp. 281-304, 1996.

[11] F. Kaya and I. Karagoz, "Numerical investigation of performance characteristics of a cyclone prolonged with a dipleg," Chemical Engineering Journal, vol. 151, no. 1-3, pp. 39-45, 2009.

[12] W. Peng, A. C. Hoffmann, H. W. A. Dries, M. A. Regelink, and L. E. Stein, "Experimental study of the vortex end in centrifugal separators: the nature of the vortex end," Chemical Engineering Science, vol. 60, no. 24, pp. 6919-6928, 2005.

[13] A. Raoufi, M. Shams, M. Farzaneh, and R. Ebrahimi, "Numerical simulation and optimization of fluid flow in cyclone vortex finder," Chemical Engineering and Processing: Process Intensification, vol. 47, no. 1, pp. 128-137, 2008.

[14] B. Wang, D. L. Xu, K. W. Chu, and A. B. Yu, "Numerical study of gas-solid flow in a cyclone separator," Applied Mathematical Modelling, vol. 30, no. 11, pp. 1326-1342, 2006.

[15] S. Bernardo, M. Mori, A. P. Peres, and R. P. Dionísio, "3-D computational fluid dynamics for gas and gas-particle flows in a cyclone with different inlet section angles," Powder Technology, vol. 162, no. 3, pp. 190-200, 2006.

[16] J. Gimbun, T. G. Chuah, A. Fakhru'l-Razi, and T. S. Y. Choong, "The influence of temperature and inlet velocity on cyclone pressure drop: a CFD study," Chemical Engineering and Processing: Process Intensification, vol. 44, no. 1, pp. 7-12, 2005.

[17] I. K. Kim and J. S. Kim, "A study on flow performance of axial inlet cyclone for dust collector," Key Engineering Materials, vol. 326-328, pp. 1321-1324, 2006.

[18] T. Yalcin, E. Kaukolin, and A. Byers, "Axial inlet cyclone for mineral processing applications," Minerals Engineering, vol. 16, no. 12, pp. 1375-1381, 2003.

[19] FLUENT User's Guide, Fluent incorporated. 


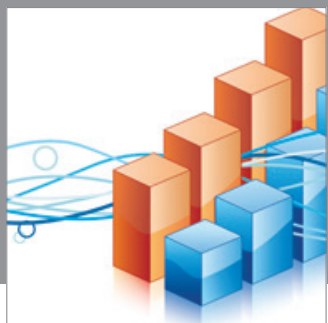

Advances in

Operations Research

mansans

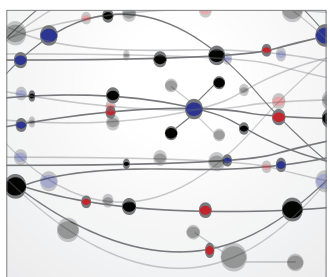

The Scientific World Journal
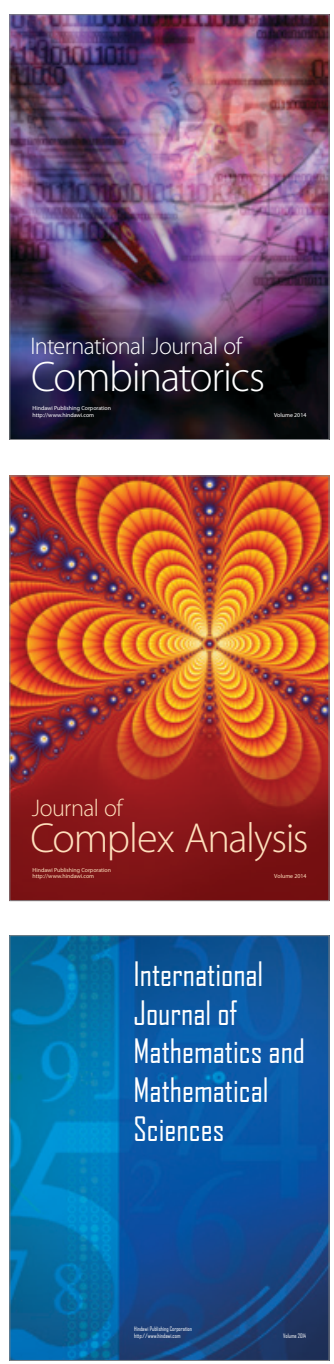
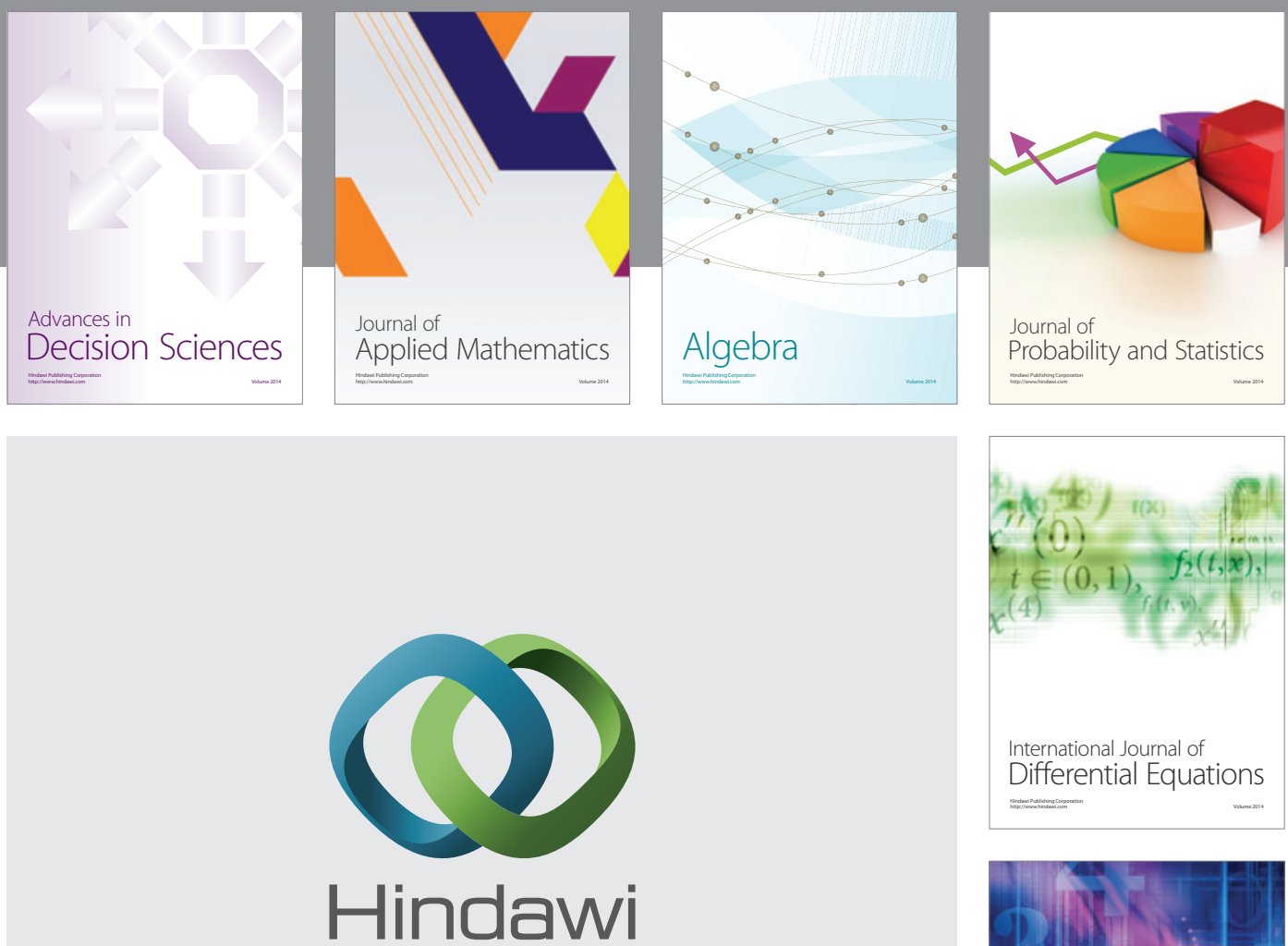

Submit your manuscripts at http://www.hindawi.com
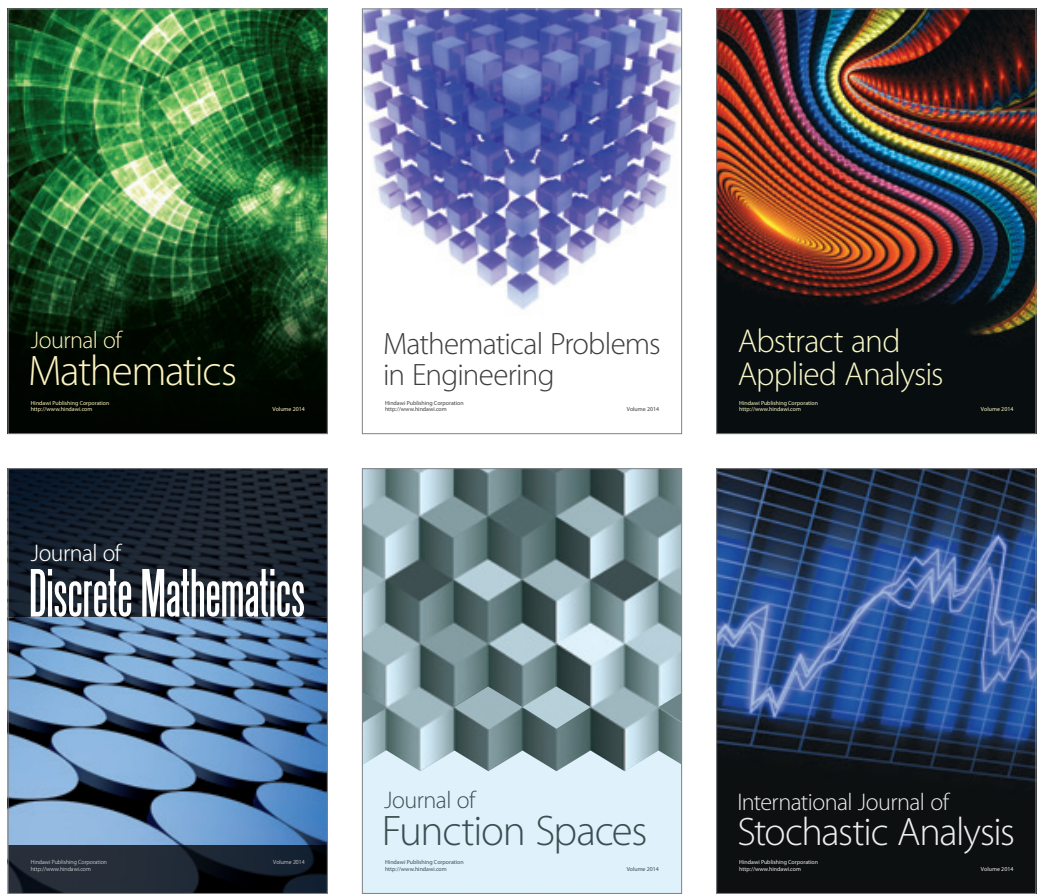

Journal of

Function Spaces

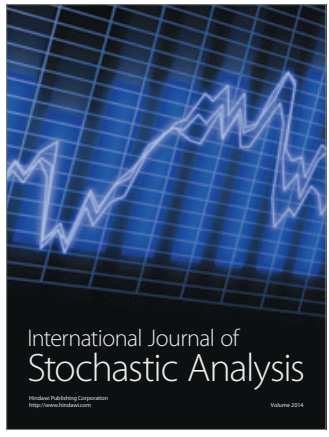

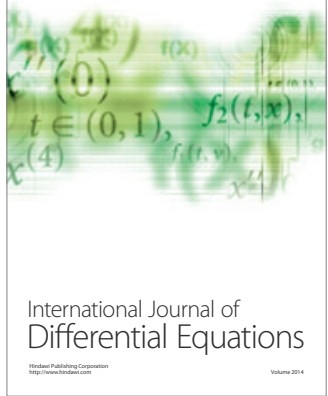
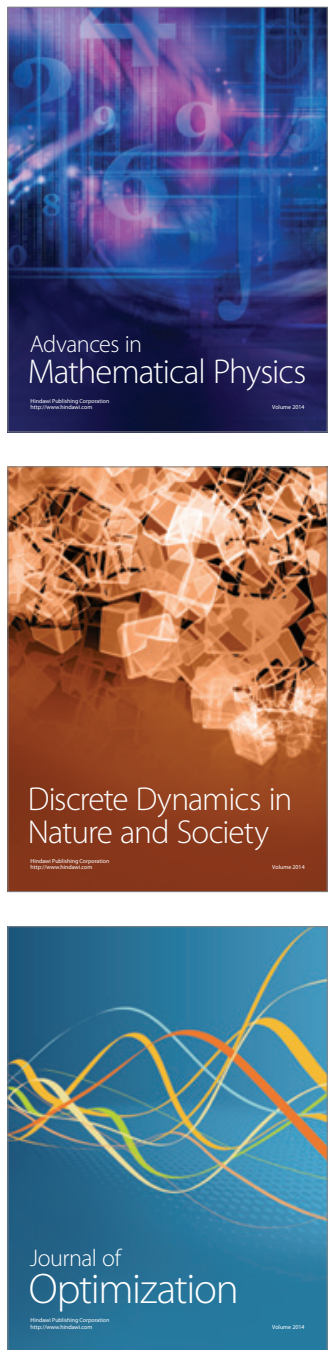